\title{
Exploring the Identification and Effects of “Opinion Leader" under Different Information Release Strategies
}

\author{
Si Yang \\ College of Business Administration, South China University of Technology, Guangzhou, China \\ Email: ouyangsi83@163.com
}

How to cite this paper: Yang, S. (2018) Exploring the Identification and Effects of "Opinion Leader" under Different Information Release Strategies. Social Networking, 7, 156-169.

https://doi.org/10.4236/sn.2018.73013

Received: May 17, 2018

Accepted: July 20, 2018

Published: July 23, 2018

Copyright $\odot 2018$ by author and Scientific Research Publishing Inc. This work is licensed under the Creative Commons Attribution International License (CC BY 4.0).

http://creativecommons.org/licenses/by/4.0/

\section{c) (i) Open Access}

\begin{abstract}
This paper systematically analyzes the models and processes related to wordof-mouth spreading in social networks. This paper simulates the characteristics and rules of word-of-mouth spreading on social network platforms, adopts network evolution models as well as virus spreading models which can precisely reflect the process of word-of-mouth spreading. By computer simulation, the effect of several kinds of parameters in networks and in wordof-mouth spreading model is analyzed. What has been proved, through parameter analysis, is that the secondary "push" of the key node (opinion leader) in social networks has played a significant role in promoting word-of-mouth spreading. In practical applications, shopkeepers can act appropriately to the situation, which means they put in a second period of advertise appropriately after placing one advertisement at random in order to save costs and increase efficiency.
\end{abstract}

\section{Keywords}

Social Network, Nodes Influence, Online Word-of-Mouth, Multi-Agent Simulation

\section{Introduction}

More and more companies are aware of the status of social media in the wordof-mouth spreading process. For the past few years, with the tremendous popularity of e-commerce and e-payment, online shopping has already become a preferred choice for most consumers in the market. As a new social media in recent years, Weibo realizes information sharing, dissemination and acquisition based on user relationships. Through the internet terminal, the users update the 
information with a text of no more than 140 words, realizing instant sharing. According to the latest statistics released by the China Internet Network Information Center (CNNIC), as of June 2017, the number of online shopping users in China reached 514 million. Among them, the annual average number of deals per capita is more than once per week, and the annual amount is close to 10,000 Yuan (10,025 for men and 8559 for women). This makes the new economic system based on online retailing and platform economy, become a point for future economic development. Companies are faced with important issues such as how to measure the effectiveness of social media and how to effectively carry out marketing activities such as microblogging marketing.

Unlike traditional retail outlets with limited goods shelves, online retail outlets place all products for customers' selection. However, online shopkeepers also need product shopping guides/consultants to introduce and recommend products to potential customers, so as to avoid customers losing during the search and selection process because of the numerous alternative products. Therefore, how to attract the attention of potential consumers, that is, "eyeballs", has become a hot issue for product suppliers under the platform economy.

Among all various online marketing strategies, friend recommendation is one of the most efficient marketing strategies. The friend recommendation referred to in this article refers to the supplier inviting some users with great charis$\mathrm{ma} / \mathrm{impact}$ to recommend products to their friends or fans. Owing to the recommendation and promotion of these great users, the word-of-mouth spreading and product purchase will be triggered. Given that friends recommend, a "spontaneous" marketing approach, product suppliers can quickly push products to potential customers in the market at the cost of "zero cost". What's more, the "friendship" between the sender and receiver makes the recommended effect much higher than traditional advertising marketing. Thus, user recommendation becomes the most successful online marketing pattern. For example, WeChat marketing, Weibo marketing, and Twitter marketing in practice are all successful applications of this type of online marketing.

In a word, how to select the most influential product "spokesperson"/“opinion leader" among potential customers has become the key to the online marketing. Furthermore, how to evaluate the investment return rate of the product is also considered.

Based on this economic environment and marketing trends mentioned above, this paper put forward the search and evaluation method for the best product "spokesperson"/"opinion leader" and the best information release strategies through tests and a series of data analysis.

\section{Related Work}

Friends recommendation in online marketing is a popular term for online word-of-mouth marketing. Among them, the most influential "spokesperson" is an opinion leader in the potential customer network (social network), which 
means, those key nodes can influence the trend of public opinion in information diffusion.

With the vigorous development of online marketing, the search algorithm or evaluation method for opinion leaders in the potential customer relationship network has become a research focus in multiple crossover fields including complex network analysis, data mining, and word-of-mouth marketing. For example, Liu Zhiming [1] combined micro-blog opinion leaders with user's influence and user's activity to identify opinion leaders, and analyzed their characteristics; $\mathrm{He} \mathrm{Li} \mathrm{[2]} \mathrm{used} \mathrm{data} \mathrm{mining} \mathrm{techniques} \mathrm{to} \mathrm{obtain} \mathrm{information} \mathrm{related} \mathrm{to}$ microblog user characteristics. After analysis, it revealed the feasibility of personalized marketing among Weibo users; Zhang J et al. [3] analyzed the effect of network structure, different characteristics in the word-of-mouth spreading process, and opinion leaders' status; Li F [4] proposed an evaluation index system based on the analysis of social networks; Java et al. [5] also analyzed the topological structure of different types of social networks, such as web-based and micro-blog network, adopting data mining methods, and finally obtained their spreading characteristics.

The identification research of opinion leaders by domestic scholars mainly focus on several node centrality [6] [7]. Table 1 gives information on representative work in recent years.

Table 1 showed some frequently-used nodes centrality index. In addition, the network of users is often obtained by adopting a scale-free network generation algorithm, and the virus SIR model is often applied to word-of-mouth marketing.

Among all evaluation methods and selection strategies for key nodes in information diffusions research field, we find that these key nodes are usually analyzed as source nodes. For information that appears randomly in the network,

Table 1. Identification algorithm for opinion leaders/key nodes in relationship network.

\begin{tabular}{|c|c|c|c|}
\hline Papers & Network types & Diffusion models & Key nodes index \\
\hline Han Zhongming [8] & Real network & $\begin{array}{l}\text { Viral spreading SIR } \\
\text { model }\end{array}$ & $\begin{array}{l}\text { Closeness centrality; } \\
\text { betweenness centrality }\end{array}$ \\
\hline Su Zhen [9] & $\begin{array}{l}\text { Scale-free } \\
\text { network }\end{array}$ & $\begin{array}{l}\text { Viral spreading SI } \\
\text { model }\end{array}$ & $\begin{array}{l}\text { Point centrality; Closeness } \\
\text { centrality; Betweenness } \\
\text { centrality; Eigenvector centrality }\end{array}$ \\
\hline Ren Zhuoming [10] & Real network & $\begin{array}{l}\text { Viral spreading SIR } \\
\text { model }\end{array}$ & K-corecentrality \\
\hline Yuan Weiguo [11] & $\begin{array}{l}\text { Sinaweibo } \\
\text { network }\end{array}$ & $\begin{array}{l}\text { Viral spreading SIR } \\
\text { model }\end{array}$ & $\begin{array}{l}\text { Point centrality; Closeness } \\
\text { centrality; Betweenness } \\
\text { centrality; K-corecentrality }\end{array}$ \\
\hline Zhao Zhiying [12] & Real network & $\begin{array}{l}\text { Viral spreading SIR } \\
\text { model }\end{array}$ & $\begin{array}{c}\text { The number of clubs connected to } \\
\text { the node }\end{array}$ \\
\hline Xiao Weidong [13] & $\begin{array}{l}\text { E-R random } \\
\text { network }\end{array}$ & Mathematical analysis & Kirchhoff index \\
\hline SuChangming [14] & Real network & $\begin{array}{l}\text { Viral spreading SIR } \\
\text { model }\end{array}$ & $\begin{array}{l}\text { Point centrality; Closeness } \\
\text { centrality; Betweenness } \\
\text { centrality; Page Rank value }\end{array}$ \\
\hline
\end{tabular}


which nodes can effectively promote the diffusion of information in the form of forwarding or recommendation is an important issue which is underestimated by experts in the relatively field, and the question whether and which selection strategies of different key nodes in the secondary "push" process will change the spreading effects is also ignored by most researchers.

This paper adopts computer simulation research methods, firstly applying the above questions in this field to explore the identification methods and algorithms of these important "secondary" recommended user nodes.

\section{Information Diffusion Practice on Online Social Network}

\subsection{Complex Network Analysis in Online Social Network}

According to previous research, considering snowball-type network reconstruction for social networks and tracing back to information diffusion examples, the online social networks are defined as scale-free networks. Besides, considering several social networks, such as Twitter, a popular microblogging system abroad [5], Sina Weibo, the domestic popular microblogging system [11] [15], or Zhihu, the professional FAQs platform, the small-world feature is also widely acknowledged (scale-free is another feature). Therefore, regardless of the data acquisition method or the actual network platform studied, it can be determined that the researched social network platform is a typical small-world network.

Based on the analysis above, this paper selects the small-world network as a platform for the research on word-of-mouth spreading. Moreover, given the authority of the Watts-Strogatz algorithm in the small-world network generation algorithm, this paper will also use this algorithm to generate a small-world network and analyze the process and information diffusion results [16].

\subsection{Analysis of Information Diffusion Process Model}

In the research of the information diffusion models on social networks, the viral information diffusion model is regarded as the most widely used and validated model [17]. The viral information diffusion model, SIR model which we adopt in this paper, has defined the state and state transition rules of nodes. Specifically, the SIR model assumes that all nodes did not obtain information at the initial time, that is, there was no susceptible state nodes ( $\mathrm{S}$ state) infected by virus. The entire information diffusion process is as follows:

1) Select one node randomly from all S-state nodes as the only source node for information diffusion. Then update the state of this node to infected state (I state).

2) Node A is randomly selected from the "I state" nodes. Then a neighbor node $B$ is randomly selected:

2.1) State transition rule 1: If the state of node B is "S state", the state of node B transforms to "I state", and the state of node A does not change (state I). This means that node A passes the information to node B. The state transition can be described as: 


$$
I_{A}+S_{B} \rightarrow I_{A}+I_{B}
$$

2.2) State Transition Rule 2: If the state of Node B is "I state", the state of Node $B$ remains unchanged, and the state of Node A transforms to Removed state ( $\mathrm{R}$ state). This means that node $\mathrm{A}$ finds that the neighbor has already acquired the information, and thus losing the interest in continuing to spread the information, that is, node A recovers from the virus infection and is permanently immunized. This state transition can be described as:

$$
I_{A}+I_{B} \rightarrow R_{A}+I_{B}
$$

2.3) State Transition Rule 3: If the state of Node B is "R state", the state of Node $B$ remains unchanged, and the state of Node A transforms to the Removed state ( $\mathrm{R}$ state). Similar to rule 2 , this rule indicates that node $\mathrm{A}$ finds that the neighbor has acquired the information and thus losing the interest in continuing to spread the information. This state transition can be described as:

$$
I_{A}+R_{B} \rightarrow R_{A}+R_{B}
$$

3) Repeat the above information diffusion process until there is no node with "I state" in the network. When the information diffusion platform of SIR model is homogenous or regular network, the process and result of information diffusion can also be modeled and analyzed using mean field theory [18]:

$$
\left\{\begin{array}{l}
\frac{\mathrm{d} S}{\mathrm{~d} t}=-S \cdot I \\
\frac{\mathrm{d} I}{\mathrm{~d} t}=S \cdot I-I \cdot(I+R) \\
\frac{\mathrm{d} R}{\mathrm{~d} t}=I \cdot(I+R)
\end{array}\right.
$$

We define $S, I, R$ as the proportion of nodes in the network. When $S+I+R=$ 1 ,

$$
\frac{\mathrm{d} I}{\mathrm{~d} S}=-\frac{S-(1-S)}{S} \Rightarrow R_{\infty} \approx 0.796
$$

Equation (5) shows that the final result of information diffusion is that $79.6 \%$ of nodes in the network will obtain information (state $\mathrm{R}$ ), while the remaining $20.4 \%$ of nodes will not obtain information (state S).

By the way, when the social network is a heterogeneous network, that is, when the distribution of nodes in the network is unevenly distributed and randomly distributed, the process and results of information diffusion are difficult to analyze using the mean field theory [18]. At this point, the only method is computer simulation analysis.

\subsection{Analysis of the Practice of "Opinion Leader" in Information Diffusion}

As mentioned above, in the practice of word-of-mouth information spreading, the role of key nodes has been accepted by the industry. However, how to choose and how to evaluate the nodes in the process of information diffusion is still in 
an explorable state, and it basically adopts the analysis of the source node.

Take the latest statistical data published on Sina Weibo as an example. There are about 390,000 cosmetics accounts (nodes) registered on Sina Weibo, indicating potential product choices for consumers become very difficult. It has been found that if the product supplier chooses a celebrity to help promote the product, it can always obtain a greater information diffusion effect. For example, on the Sina Weibo platform, Clinique's product promotion began on July 6, 2016. On the day that products were launched, they invited two stars to help promote their products. On July 22, the merchants again invited the two stars to promote. The entire product promotion, or we can say information diffusion campaign, attracted a total of 30.61 million fans, which attracted 860,000 fans and 70,000 followers.

Another successful product promotion activities on the Sina Weibo platform are also similar-"Lancome". The products went live on December 16, 2016. Three days later, three celebrities were invited to help promote products, bringing the products topic exposure up to 45.27 million times.

These cases can sum up the following two empirical rules of practice:

1) After the product supplier releases the product information, a very short time later, they start up some important nodes to launch information promotion activities.

2) Product suppliers often choose celebrity stars because of the fact that important nodes help push information.

It also shows that in practical applications, the companies (source node) usually publishes information and simply selects the node with the largest degree of network to promote information diffusion.

This paper will represent the actual social network in a scale-free network and use the SIR model of virus diffusion as a diffusion model for information diffusion.

For the selection of important promoter nodes in information diffusion, based on previous research results and combined with practical experience, this paper will compare and test various options, including the point centrality, closeness centrality, and between nesscentrality, to obtain their characteristic and effect.

\section{Simulation Analysis of Information Diffusion Process}

Based on the previous work, this paper adopts the information diffusion model on the scale-free network with the multi-agent modeling and simulation platform Netlogo 6.01. The parameters of WS small-world network algorithm are: the total number of nodes $N=6400$; the average degree of nodes $k=4$, the reconnection probability of the links between the nodes is $p=0.20$, and the triggered time of the second "push" process $T_{p}=5$.

\subsection{Process and Result Analysis of Information Diffusion}

When considering the role of the secondary "push" node in information diffu- 
sion, we adjust the second step in the standard SIR model, that is, instead of randomly selecting one node A from the "I state" nodes for information diffusion, we consciously choose a node for information diffusion from the "S state" nodes. The specific diffusion process is shown as follows:

1) Select one node randomly from all "S state" nodes as the only source node for information diffusion. Update the state of this node to infected state (I state). At the same time, set the simulation clock $T$ to 0 , the initial state.

2) If the simulation clock $T$ value is less than $T_{p}$, follow the rules and procedures of information diffusion in the standard SIR model. That is, one node A is randomly selected from the "I state" nodes. From the set of connected nodes of $A$, one neighbor node B is randomly selected. If the state of the node B is " $\mathrm{S}$ state", the state of the node B is updated to the "I state", and the state of the node A does not change; if the state of the node B is "I" or "R", the state of the node B remains unchanged, and the state of the node $\mathrm{A}$ is updated to $\mathrm{R}$ status. At the same time, the simulation clock $T$ is advanced one unit, i.e. $T=T+1$.

3) If the value of the simulation clock $T$ is equal to $T_{p}$, the secondary "push" of information diffusion is triggered. At this time, according to certain rules, one node is selected from all "S state" nodes as a secondary "push" node, then is updated to "I state". At the same time, the simulation clock $T$ is advanced one unit, i.e. $T=T+1$.

4) If the simulation clock $T$ value is greater than $T_{p}$, reoperate the rules and procedures for information diffusion in the standard SIR model. At the same time, the simulation clock $T$ is advanced one unit, i.e. $T=T+1$.

5) Repeat the above process until there is no node with "I state" in the network. The following gives the selection strategies of the secondary "push" node often used in practice-the node with the largest degree. Analyze the single simulation process and result when $T_{p}=5$.

Figure 1 shows the results of a single simulation with standard SIR model. Comparing the results of the two simulations, it can be seen that although the information spreading speed is faster in the standard SIR model, that is, the ratio of the "I node" in Figure 1(a) is reduced to 0 earlier (simulation clock $T=325$ ), but the spreading rate of the information diffusion network under secondary "push" is even greater $(=0.5375)$, which means the ratio of the " $\mathrm{R}$ state" node in Figure 1(b) is greater. The role of the "push" nodes can be concluded from this result.

Repeat the simulations 500 times, and get the final result of information diffusion under the second "push" spreading:

In Table 2, it can be seen that under the push of the node with the largest degree, the information spreads more widely than the situation without its function, around 2.49 times $(=0.0620 / 0.0249)$.

\subsection{How to Select a Secondary "Push" Node}

Based on previous research, this paper continues to test and compare the information diffusion of three different nodes selection strategies. Specifically, it 


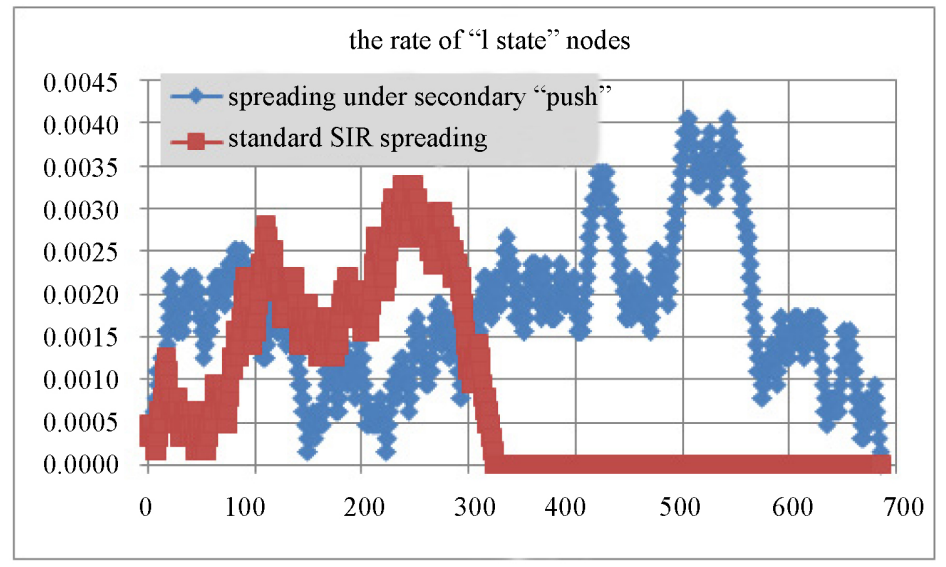

(a)

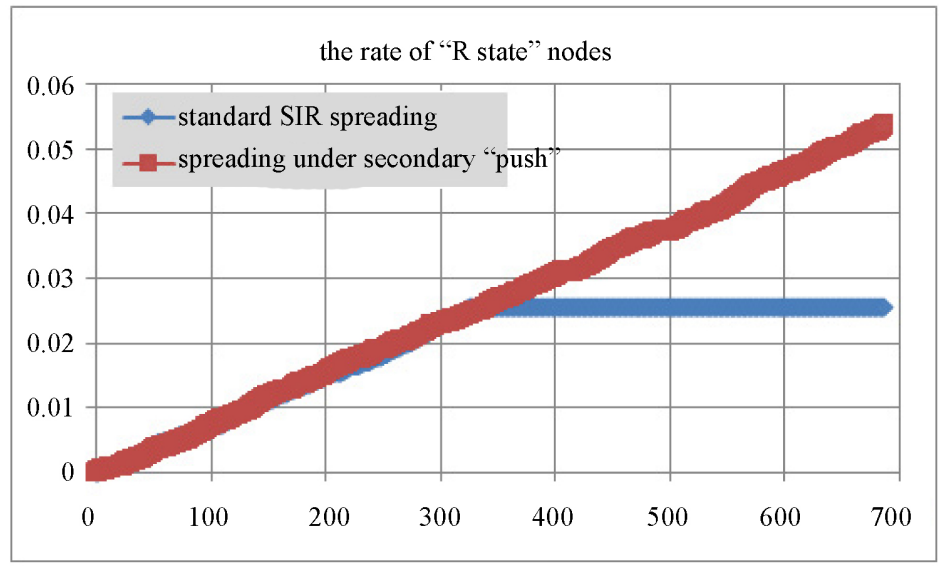

(b)

Figure 1. Single simulation process data.

Table 2. Statistics of simulation results.

\begin{tabular}{ccccc}
\hline & $\begin{array}{c}\text { mean of total } \\
\text { simulation duration }\end{array}$ & $\begin{array}{c}\text { confidence } \\
\text { interval }(95 \%)\end{array}$ & $\begin{array}{c}\text { Mean of R } \\
\text { state ratio }\end{array}$ & $\begin{array}{c}\text { confidence } \\
\text { interval (95\%) }\end{array}$ \\
\hline $\begin{array}{c}\text { Spreading under } \\
\text { secondary "push" } \\
\text { Standard SIR } \\
\text { spreading }\end{array}$ & 718.332 & {$[644.9368,791.7272]$} & 0.0620 & {$[0.0505,0.0620]$} \\
\hline
\end{tabular}

includes strategies: the node with the largest degree centrality, the node with the largest closeness centrality and the largest betweenness centrality.

As shown in Table 3, on the same network, the node with the largest degree centrality has the best promotion effect on the information diffusion: the information spreads faster and more widely. This shows that the choice in reality is quite scientific and reasonable.

\subsection{The Effect of Reconnection Probability $p$ in Small-World Networks}

According to the description of the Watts-Strogatz small-world network algorithm, when the probability of reconnection probability $p$ is approximate to 0 , 
Table 3. Effects comparison under different "push" nodes selection strategies.

\begin{tabular}{ccccc}
\hline Selection of "push" nodes & $\begin{array}{c}\text { mean of total } \\
\text { simulation } \\
\text { duration }\end{array}$ & $\begin{array}{c}\text { confidence interval } \\
(95 \%)\end{array}$ & $\begin{array}{c}\text { Mean of R } \\
\text { state ratio }\end{array}$ & $\begin{array}{c}\text { confidence interval } \\
(95 \%)\end{array}$ \\
\hline $\begin{array}{c}\text { The largest point } \\
\text { centrality }\end{array}$ & 718.332 & {$[644.9368,791.7272]$} & 0.0620 & {$[0.0505,0.0620]$} \\
$\begin{array}{c}\text { The largest closeness } \\
\text { centrality }\end{array}$ & 747.788 & {$[676.3382,819.2378]$} & 0.0585 & {$[0.0530,0.0641]$} \\
$\begin{array}{c}\text { The largest betweenness } \\
\text { centrality }\end{array}$ & 767.002 & {$[690.5360,843.4680]$} & 0.0600 & {$[0.0541,0.0660]$} \\
\hline
\end{tabular}

the network is approximate to a regular network; When the reconnection probability $p$ is approximate to 1 , the network is approximate to ER random network.

Table 4 shows the effect of reconnection probability $p$ on the information diffusion under the premise that the number of nodes in the network $N=6400$ and the average degree of nodes $\langle k\rangle=4$.

The data in Table 4 is shown in the form of line graph, which clearly contrasts the influence of the second "push" nodes on the spreading process.

In Figure 2, we can conclude:

1) It has a significant role in promoting information diffusion, whichever strategies you choose;

2) With the increase of $p$ value, the original network diameter become more and more small, and it gradually stabilizes at 14 , and the ratio of received nodes gradually stabilized at 0.35 .

3) When the $p$ value is close to 0 or close to 1 , the secondary "push" effect of the node is not obvious. When the $p$ value approaches to 0.5 , the secondary "push" effect of the node is very obvious.

4) From Figure 2(d) we can say that the influence of three different nodes is nearly the same, and no node has obvious advantages.

In addition, we compare the total duration time of information spreading.

In Figure 3, it can be seen that with the effect of the secondary "push" node, the duration time for information diffusion has increased significantly, but there is no significant difference between the three different nodes selection strategies.

\subsection{The Effect of Average Degree $<k>$ in Small-World Network}

In order to make the analysis on the network characteristics more complete, here we set the average degree of the network respectively as $2,4,6,8,10,12,14,16,18$, $20,22,24,26,28,30$, and set the network nodes size as 6400 , the p value of the network as 0.2 . The total duration time and final $\mathrm{R}$ ratio are shown in Table 5.

The data in Table 5 is shown in the Figure 4 in the form of line graph.

In Figure 4, it can be seen that, as the average degree of the network increases, the ratio of the final receiver of word-of-mouth spreading is getting larger and larger, and the duration time is much longer. However, when the average degree reaches 16 or above, the ratio and duration time both vary little, which means that social network operators do not need to make a network too compact 


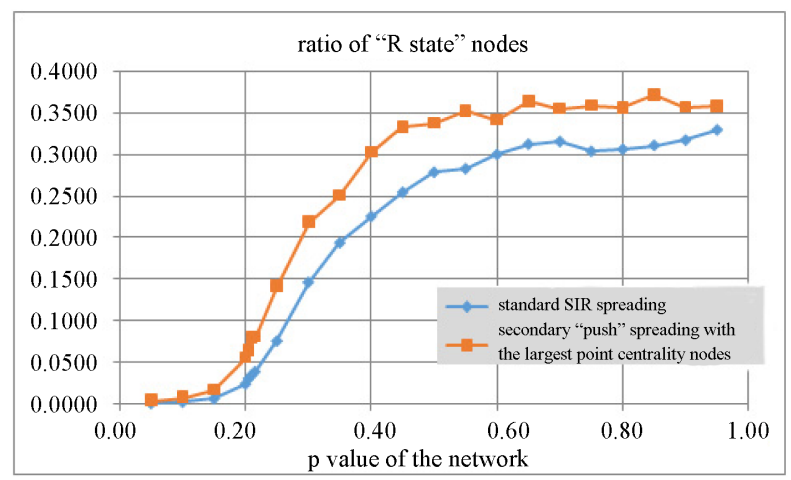

(a)

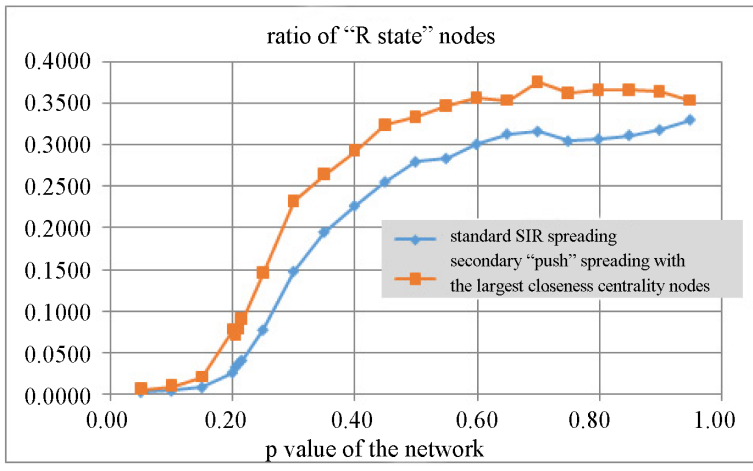

(b)

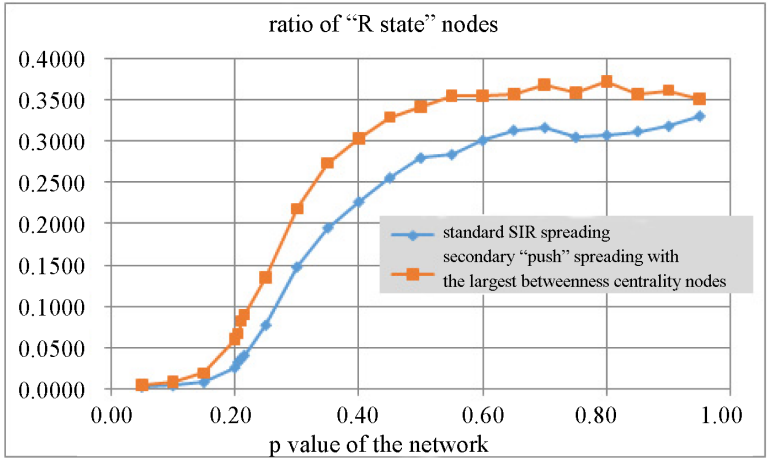

(c)

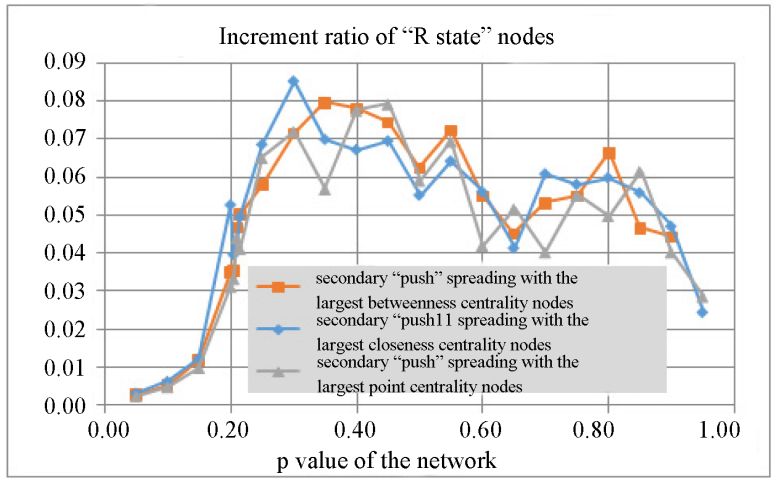

(d)

Figure 2. Data comparison under different secondary "push" nodes selection strategies. 


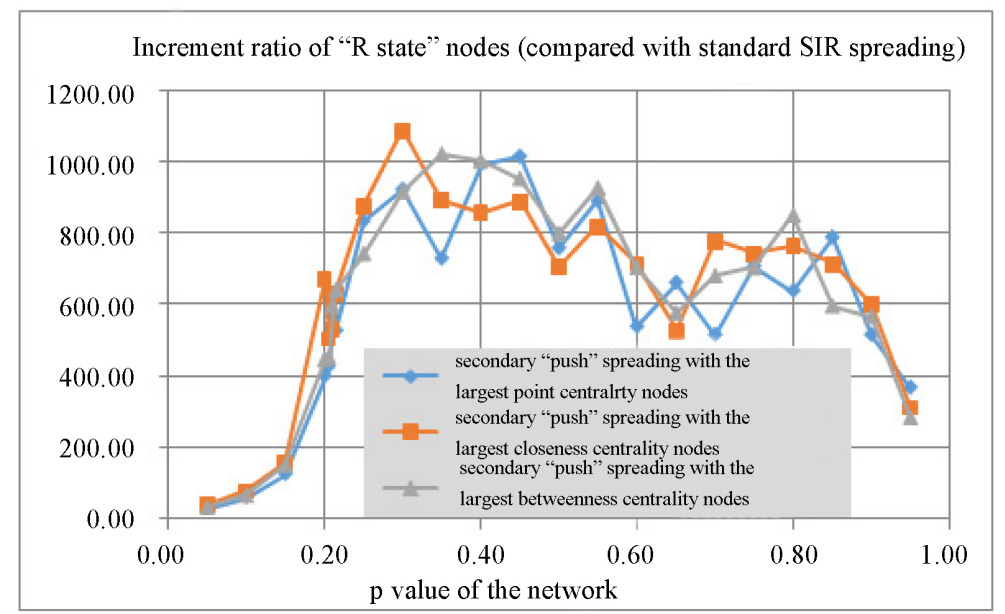

Figure 3. Comparison of the total duration time under different secondary "push" nodes selection strategies.

Table 4. Data comparison under different secondary "push" nodes selection strategies.

\begin{tabular}{|c|c|c|c|c|c|c|c|c|c|}
\hline \multicolumn{2}{|c|}{$\begin{array}{l}\text { Small-world } \\
\text { network }\end{array}$} & \multicolumn{2}{|c|}{$\begin{array}{l}\text { Standard } \\
\text { SIR model }\end{array}$} & \multicolumn{2}{|c|}{$\begin{array}{c}\text { The largest point } \\
\text { centrality }\end{array}$} & \multicolumn{2}{|c|}{$\begin{array}{l}\text { The largest } \\
\text { closeness } \\
\text { centrality }\end{array}$} & \multicolumn{2}{|c|}{$\begin{array}{c}\text { The largest } \\
\text { betweenness } \\
\text { centrality }\end{array}$} \\
\hline$p$ & $\begin{array}{l}\text { Network } \\
\text { diameter }\end{array}$ & $\begin{array}{l}\text { Duration } \\
\text { time }\end{array}$ & Rratio & $\begin{array}{l}\text { Duration } \\
\text { time }\end{array}$ & Rratio & $\begin{array}{c}\text { Duration } \\
\text { time }\end{array}$ & Rratio & $\begin{array}{l}\text { Duration } \\
\text { time }\end{array}$ & $\mathrm{R}$ ratio \\
\hline 0.05 & 34 & 20.596 & 0.0017 & 52.252 & 0.0042 & 59.794 & 0.0048 & 56.328 & 0.0045 \\
\hline 0.10 & 23 & 38.808 & 0.0031 & 101.124 & 0.0080 & 117.704 & 0.0093 & 108.236 & 0.0086 \\
\hline 0.15 & 19 & 92.904 & 0.0073 & 220.104 & 0.0173 & 248.672 & 0.0196 & 246.586 & 0.0194 \\
\hline 0.20 & 17 & 318.372 & 0.0250 & 718.332 & 0.0563 & 991.706 & 0.0776 & 767.002 & 0.0601 \\
\hline 0.25 & 16 & 980.116 & 0.0767 & 1814.36 & 0.1419 & 1856.814 & 0.1452 & 1723.770 & 0.1348 \\
\hline 0.30 & 16 & 1882.748 & 0.1472 & 2804.904 & 0.2193 & 2972.468 & 0.2324 & 2799.314 & 0.2188 \\
\hline 0.35 & 16 & 2490.560 & 0.1947 & 3219.996 & 0.2517 & 3384.710 & 0.2646 & 3510.996 & 0.2744 \\
\hline 0.40 & 14 & 2895.092 & 0.2263 & 3889.334 & 0.3040 & 3753.914 & 0.2934 & 3896.164 & 0.3045 \\
\hline 0.45 & 15 & 3267.208 & 0.2553 & 4282.026 & 0.3347 & 4155.902 & 0.3248 & 4219.864 & 0.3298 \\
\hline 0.50 & 14 & 3576.952 & 0.2795 & 4335.120 & 0.3388 & 4283.236 & 0.3348 & 4376.566 & 0.3421 \\
\hline 0.55 & 14 & 3629.068 & 0.2836 & 4518.998 & 0.3532 & 4450.038 & 0.3478 & 4555.460 & 0.3560 \\
\hline 0.60 & 14 & 3849.196 & 0.3008 & 4387.794 & 0.3429 & 4566.852 & 0.3569 & 4554.350 & 0.3560 \\
\hline 0.65 & 14 & 4006.088 & 0.3131 & 4668.216 & 0.3649 & 4534.188 & 0.3544 & 4584.274 & 0.3583 \\
\hline 0.70 & 14 & 4046.584 & 0.3142 & 4562.458 & 0.3566 & 4824.530 & 0.3771 & 4728.352 & 0.3696 \\
\hline 0.75 & 13 & 3898.420 & 0.3046 & 4606.174 & 0.3600 & 4641.094 & 0.3627 & 4602.996 & 0.3598 \\
\hline 0.80 & 14 & 3928.872 & 0.3070 & 4567.662 & 0.3570 & 4693.826 & 0.3669 & 4778.974 & 0.3735 \\
\hline 0.85 & 13 & 3987.024 & 0.3116 & 4775.470 & 0.3732 & 4701.634 & 0.3675 & 4584.954 & 0.3583 \\
\hline 0.90 & 15 & 4069.820 & 0.3180 & 4585.732 & 0.3584 & 4671.394 & 0.3651 & 4638.310 & 0.3625 \\
\hline 0.95 & 13 & 4226.076 & 0.3302 & 4594.094 & 0.3591 & 4537.996 & 0.3547 & 4512.442 & 0.3527 \\
\hline
\end{tabular}

overmuch. What's more, whether selecting the largest point centrality node, or the largest closeness centrality node, and the largest betweenness centrality node 
Table 5. Data comparison of different "push" nodes selection strategies when average degree varies.

\begin{tabular}{ccccccccc}
\hline$p=0.2$ & \multicolumn{2}{c}{ Standard SIR model } & \multicolumn{2}{c}{$\begin{array}{c}\text { The largest point } \\
\text { centrality }\end{array}$} & \multicolumn{2}{c}{$\begin{array}{c}\text { The largest closeness } \\
\text { centrality }\end{array}$} & $\begin{array}{c}\text { The largest betweenness } \\
\text { centrality }\end{array}$ \\
\hline$<k>$ & $\begin{array}{c}\text { Duration } \\
\text { time }\end{array}$ & Rratio & $\begin{array}{c}\text { Duration } \\
\text { time }\end{array}$ & Rratio & $\begin{array}{c}\text { Duration } \\
\text { time }\end{array}$ & Rratio & Duration time & R ratio \\
\hline 2 & 9.13 & 0.0014 & 16.53 & 0.0014 & 18.25 & 0.0015 & 19.82 & 0.0016 \\
4 & 317.69 & 0.0248 & 678.29 & 0.0531 & 706.55 & 0.0553 & 737.28 & 0.0577 \\
6 & 4757.86 & 0.3717 & 5816.29 & 0.4545 & 5958.51 & 0.4656 & 5855.15 & 0.4575 \\
8 & 7432.44 & 0.5807 & 7856.74 & 0.6139 & 7845.71 & 0.6130 & 7880.78 & 0.6158 \\
10 & 8498.54 & 0.6640 & 8707.32 & 0.6804 & 8777.18 & 0.6858 & 8801.56 & 0.6877 \\
12 & 9159.06 & 0.7156 & 9191.05 & 0.7182 & 9202.71 & 0.7191 & 9204.32 & 0.7192 \\
14 & 9345.47 & 0.7301 & 9459.28 & 0.7391 & 9474.93 & 0.7403 & 9457.28 & 0.7390 \\
16 & 9603.99 & 0.7503 & 9573.00 & 0.7480 & 9601.26 & 0.7502 & 9597.39 & 0.7499 \\
18 & 9715.11 & 0.7590 & 9707.89 & 0.7585 & 9709.13 & 0.7586 & 9714.31 & 0.7590 \\
20 & 9763.25 & 0.7628 & 9766.22 & 0.7631 & 9793.76 & 0.7652 & 9779.12 & 0.7641 \\
22 & 9808.23 & 0.7663 & 9835.51 & 0.7685 & 9814.42 & 0.7669 & 9855.81 & 0.7701 \\
24 & 9822.58 & 0.7674 & 9869.26 & 0.7711 & 9845.29 & 0.7693 & 9866.47 & 0.7709 \\
26 & 9923.60 & 0.7753 & 9896.90 & 0.7733 & 9895.55 & 0.7732 & 9914.22 & 0.7747 \\
28 & 9939.27 & 0.7766 & 9926.37 & 0.7756 & 9905.93 & 0.7740 & 9945.53 & 0.7771 \\
30 & 9952.32 & 0.7776 & 9966.13 & 0.7787 & 9961.64 & 0.7784 & 9959.85 & 0.7782 \\
\hline
\end{tabular}

to perform the secondary spreading will have no significant effect on the final result of word-of-mouth spreading.

\section{Conclusions}

From the information diffusion simulation and parameter analysis above, we draw the following conclusions:

1) Compared with once spreading, the secondary "push" spreading is more significant in promoting word-of-mouth spreading, making word-of-mouth have more receivers on the Internet and more endurable.

2) With the increase of $p$-value, the original network diameter become more and more small, and the corresponding result of information diffusion is gradually stabilized at a certain value. When the $p$-value is close to 0 and the $\mathrm{p}$ value is close to 1 , the secondary "push" effect of the node is not obvious. When the $p$ value approaches to 0.5 , the secondary pushing effect of the node is very obvious.

3) With the increase of average degree, the ratio of information receiver becomes more and more large. When the average degree is close to a certain value, the ratio of receiver nodes and the duration time will not vary drastically.

Based on computer multi-agent simulation, this paper unites the relevant methods of spreading dynamics, concerns on some hot issues concluding 


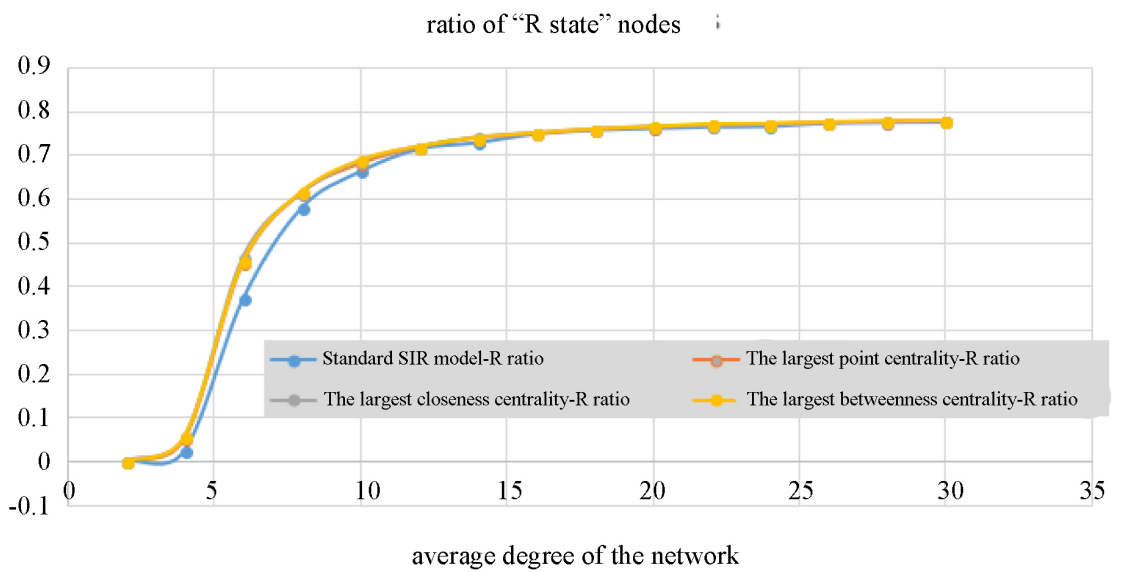

(a)

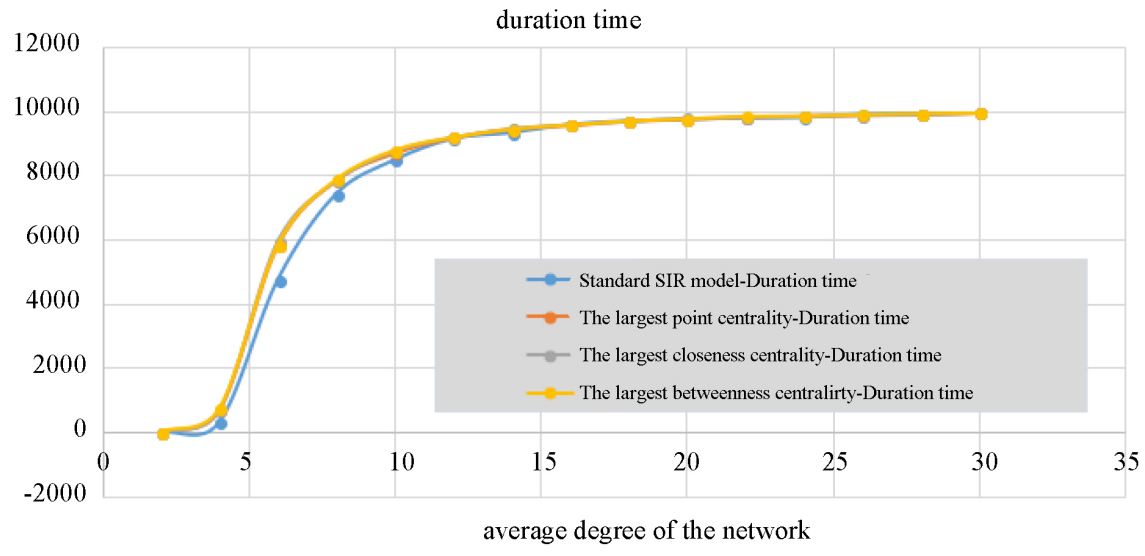

(b)

Figure 4. (a) Comparison of the ratio of "R state" nodes when the average degree varies; (b) Comparison of the duration time when the average degree varies.

information dissemination process in social network, network topology, information delivery strategies, nodes influence analysis and influence maximization of propagation. The results not only help relevant researchers deepen their understanding of complex network research, but also enrich the theory of individual interaction behavior and information dissemination in social networks, and also effectively help solve practical problems such as advertising strategies, internet-marketing, public opinion control, etc.

\section{References}

[1] Liu, Z.M. and Liu, L. (2011) Recognition and Analysis of Opinion Leaders in Microblog Public. System Engineering, 6, 8-16.

[2] He, L., He, Y. and Huo, Y.Q. (2011) User Feature Analysis and Core User Mining on Weibo Network. Information Studies: Theory \& Application, 34, 121-125.

[3] Zhang, J., Liu, Y. and Che, Y. (2015) Social Learning in Networks of Friends versus Strangers. Marketing Science, 34, 573-589. https://doi.org/10.1287/mksc.2015.0902

[4] Li, F. and Du, C.T. (2014) Listen to Me-Evaluating the Influence of Micro-Blogs. 
Decision Support Systems, 62, 119-130. https://doi.org/10.1016/j.dss.2014.03.008

[5] Java, A., Song, X., Finin, T., et al. (2007) Why We Twitter: Understanding Microblogging Usage and Communities. Webkdd and, Sna-Kdd 2007 Workshop on Web Mining and Social Network Analysis. ACM, 56-65.

[6] Ren, X.L. and Lv, L.Y. (2014) Review of Ranking Nodes in Complex Networks. Chinese Science Bulletin, 59, 1175-1197. https://doi.org/10.1360/972013-1280

[7] Liu, J.G., Ren, Z.M., Guo, Q. and Wang, B.H. (2013) Node Importance Ranking of Complex Networks. Acta Physica Sinica, 62, Article ID: 178901.

[8] Han, Z.M., Chen, Y., Li, M.Q., Liu, W. and Yang, W.J. (2016) An Efficient Node Influence Metric Based on Triangle in Complex Networks. Acta Physica Sinica, 65, Article ID: 168901.

[9] Su, Z., Gao, C. and Li, X.H. (2017) Analysis of the Effect of Node Centrality on Diffusion Mode in Complex Network. Acta Physica Sinica, 66, Article ID: 120201.

[10] Ren, Z.M., Liu, J.G., Shao, F., Hu, Z.L. and Guo, Q. (2017) Analysis of the Spreading Influence of the Nodes with Minimum K-Shell Value in Complex Networks. Acta Physica Sinica, 62, Article ID: 108902.

[11] Yuan, W.G., Liu, Y., Cheng, J.J. and Xiong, F. (2013) Empirical Analysis of Microblog Centrality and Spread Influence Based on Bi-Directional Connection. Acta Physica Sinica, 62, Article ID: 038901.

[12] Zhao, Z.Y., Yu, H., Zhu, Z.L. and Wang, X.F. (2014) Identifying Influential Spreaders Based on Network Community Structure. Chinese Journal of Computers, 37, 753-766.

[13] Xiao, W.D., Tan, W.T., Ge, B. and Li, F. (2013) Fast Method for Node Importance Evaluation in Network. Systems Engineering-Theory \& Practice, 33, 1898-1904.

[14] Su, C.M., Chen, D.B. and Fu, Y. (2011) Effect of Initial Infected Individuals on the Spread of Epidemics in Complex Networks. Computer Science, 38, 144-147.

[15] Fu, F., Liu, L. and Wang, L. (2008) Empirical Analysis of Online Social Networks in the Age of Web 2.0. Physica A, 387, 675-684. https://doi.org/10.1016/j.physa.2007.10.006

[16] Watts, D.J. and Strogatz, S.H. (1998) Collective Dynamics of "Small-World" Networks. Nature, 393, 440-442. https://doi.org/10.1038/30918

[17] Domenico, M.D., Lima, A., Mougel, P. and Musolesi, M. (2013) The Anatomy of a Scientific Rumor. Scientific Reports, 3, 2980. https://doi.org/10.1038/srep02980

[18] Moreno, Y., Nekovee, M. and Pacheco, A.F. (2004) Dynamics of Rumor Spreading in Complex Networks. Physical Review E, 69, 066130.

https://doi.org/10.1103/PhysRevE.69.066130 